\title{
Consumer's Shopping Values for e-Satisfaction and e-Loyalty: Moderating Effect of Personality
}

\author{
Yun Ji Moon \\ Department of Management Information Systems, Catholic University of Pusan \\ yjmoon@cup.ac.kr
}

\begin{abstract}
The current study tries to understand better how consumers' e-shopping value orientation relates to consumer's behavior in online environment. Consumers have perceptions of the e-shopping value they acquire during their experiences in navigating Web sites. This consumer's e-shopping value is considered as utilitarian shopping value, hedonic shopping value, and social engagement shopping value. The current paper proposes that value orientation of consumers in Web sites would consequently affect customer loyalty such as revisit intention and intention to Word-of-Mouth. In addition, the research investigates the moderating effect of consumer's personality between consumer's e-shopping value and consumers' attitude in Web sites. For testing the hypothesized research model, survey and Lisrel analysis are conducted. The findings emphasize that online providers need to focus on the perceived e-shopping values most salient to consumers in order to improve their profitability.
\end{abstract}

Keywords: Utilitarian Shopping Value, Hedonic Shopping Value, Social Engagement Shopping Value, Revisit Intention, Intention to Word-of-Mouth, Personality

\section{Introduction}

Customer loyalty is becoming the primary capital in the service industry. There is no question that customer loyalty increases a firm's revenue, lowers customer acquisition costs, and gives a service firm a competitive advantage. Moreover, customer loyalty is also becoming important in the online environment. More than ever before, Internet users now turn to the online channel for their transactions. While the Internet is accounting for $5.95 \%$ of the Korean GDP(fifth largest among OECD nations); this portion is larger than those of major Korean industries, such as electronics (5.91\%) and automobiles (4.93\%). Due to this intense market competition, online providers need to reveal and manage the success factors of Internet shopping businesses. In order for online and offline retailers to be as successful as possible: they musttarget the right people, know what kind of products to sell and know whether they should sellthrough an online or offline store.

Especially in the information intensive lodging industry, websites have high effects on the planning of vacations and trips. PhoCusWright, a research firm, reports that online booking now accounts for $43 \%$ of total travel sales in America and $45 \%$ in Europe. Thus, the Internet is becoming the most influential channel for travel purchases. In order to draw customers to websites and achieve further growth, the lodging industry needs to improve its technology and adopt electronic customer relationship marketing by recognizing customer needs.This research will therefore explore consumers' shopping motivations, thereby differentiating between hedonic shopping- (providing the shopper with enjoyment and fun), utilitarian shopping- (related tosuccessfully accomplishing the shopper's goal), and social engagement shopping-motivations (offering the shopper with establishing social relationship) to see how these motivations relateto online and offline shopping intentions. Thus, this study aims to explore the direct and indirect predictors of consumers'e-satisfaction and e-loyalty from the perspective of individual shopping 
motives in the online lodging industry.

First of all, e-satisfaction can be explained as a significant driver of e-loyalty in the Business to Consumer (B2C) context. In the past two decades, satisfaction has become an important determinant of loyalty in the offline context [1]. Along with the traditional effect of customer satisfaction on loyalty, this study considers another indirect driver of customer loyalty as shopping motives. In pursuing answers for online business success, the paper seeks to provide a framework for understanding personal shopping motives of online shopping behavior. Online consumers with different shopping motives have different purchase experiences [2]. In a different motivational status, for instance, some consumers could search for affective excitement aroused by the shopping situation. Consumers with affective shopping motives may feel satisfaction in case B2C website is pleasing and stimulating to the eye. On the other hand, consumers who emphasize purchasing the relatively low-cost products may be satisfied when these consumption needs are met. Based on previous consumer literature [2][3], this study divides different shopping motives into personal motives (i.e., personality) and more comprehensive goals pursued through shopping (i.e., shopping values). Both aspects of shopping motives are used to explain the willingness to make online purchases.

The paper analyzes the moderating role of consumers' personality (extraversion vs. neuroticism), which is one of the personal shopping motives. Although some of previous works have identified the potential moderation of dispositional personality traits, research related to personality is still an underdeveloped area of online consumer behavior. Shopping values and personality are applied to identify determinants of e-shopping behavior.

\section{Literature Review}

Shopping motives refer to consumers'different goals of shopping products and services, asking questions of "why do people shop?" by Tauber [4]. These different goals could motivate people to interact differently with the online website or offline store. Customer's buying choices are affected by a psychological factor of shopping motives in the purchasing process. Shopping motives are "forces instigating behavior to satisfy internal need states"[5]. In early studies on shopping motives, Tauber proposed that shopping motives include not only the covering of the product need, but also other drivers for shopping behavior that are irrelevant to the purchase of the product [4]. Other triggers for shopping behavior except the product need can be recognized as the combination of cognitive and emotional states of a person that generates a feeling within them that they need to purchase an item, as well as the dispositional factors that affect their eventual choice of a specificproduct[4][5]. Drawing from the previous consumer literature, Guidoorganized two streams of research in shopping motives: more comprehensive goals reflecting emotional and cognitive states of a shopper (i.e., shopping values) and dispositional personality motives (i.e., personality) [2].

\subsection{Shopping Values}

As a result of cognitive and emotional motives and attitudes, a consumer's perceived shopping values may lead to purchase and consumption behavior. Substantial research has addressed that shopping is instigated by the actual acquisition of products and services, as well as through the enjoyment of the shopping itself [6]. Utilitarian shopping values, which are derived from the actual buying activity of products, have the task-related meaning that a product is purchased efficiently and functional shopping goals are accomplished. As utilitarian shopping values are based on rational judgement apart from emotional feelings, value and satisfaction can be perceived when a consumer acquires his/her intended results with regard to product/service evaluations, price comparison 
features, and searching time, prior to actual purchase. As such, utilitarian shopping values can be characterized as mission-critical, rational, decision-effective, and goal-oriented [7]. Specifically, consumers with utilitarian shopping values seek a good buy of low-priced or quality merchandise and a convenient shopping [8]. The basic components of cost have been cited within the contexts of money, time, and effort that are required to be expended for consumption.

Hedonic shopping values can be obtained when a consumer experiences enjoyment and pleasure through shopping. Compared to utilitarian shopping values, hedonic shopping values focus on the intrinsic, emotional, and irrational aspects of individual buying behavior [9-11]. Consumers with hedonic shopping values purchase products or services simply because of the emotional need for an interesting and enjoyable shopping experience. For instance, consumers shopping travel-related products and services could derive hedonism when navigating through online catalogues or enjoying virtual travel experiences. Thus, hedonic shopping values are related to individual psychological playfulness rather than to task completion or goal orientation as is the case with utilitarianism. Although the emotional facet of consumption experience includes various feelings such as pleasure, arousal and dominance [12], hedonism emphasizes perceived enjoyment, in which consumers pursue epicurean and ludic goals [3].

While retailing literature has been dominated by economic and psychological approaches -utilitarian and hedonic - to examine shopping behaviors, there are also researchers within sociology and cultural disciplines who have explored the shopping phenomenon [13]. In sociocultural literature, shopping is commonly recognized as an act of consumption which incorporates more aspects than those present in the momentary store visit and thus must be understood in relation to its wider social context. In this vein, some researchers suggested that shopping gratification involves the opportunity for social interactions with friends, family or even strangers and the sensory stimulation such as exchanging new information about upcoming trends and fashion [10,11]. According to Lazarus's study [14], a consumer's assessment of a situation is affected by both internal and external factors. Internal factors refer to individual emotions that evoke enjoyment and excitement in shopping experience, while external factors indicate others' response and product functioning. In other words, Lazarus' model posits external orientation in shopping process as utilitarian as well as social engagement shopping values. Within online context, chat-rooms, blogs, and ratings, which enable consumers to have social interaction with other consumers, friends, and acquaintances, are significantly considered from the perspective of social engagement shopping values. Recently, online shopping websites provide consumers with spaces to share of not only the original contents, but also the added feedback and following opinions. This two-way communication and social presence encourage consumers to engage in co-creating value [15]. Therefore, shopping values in the current study consist of utilitarian-, hedonic-, and social engagementshopping values.

\subsection{Personality}

Research implies that there exists a relationship between psychographic characteristics such as personality features and consumer behavior [16]. Personality traits, one of the dispositional factors, are a stable set of characteristics and tendencies that determine individual's commonalities and differences in thoughts, feelings, and actions [17]. According to Eysenck et al. [18], traits are essentially dispositional factors that regularly and persistently determine our conduct in many different types and situations. The Eysenck Personality Questionnaire (EPQ) has been prominently used in personality research $[19,20]$ and has shown consistent results across a variety of samples (e.g., professionals, college students, children) in a number of countries. Eysenck et al. [18] classifies personality type into extraversion $(\mathrm{E})$, neuroticism $(\mathrm{N})$, and psychoticism $(\mathrm{P})$. Among them, some researchershighlight two of the consistently identified traits: 
Extraversion and Neuroticism [21]. Extraversion refers to the ability to engage the environment [22]. Extraverts seek out new opportunities and excitement. Neuroticism represents a lack of psychological adjustment and emotional stability and also represents the degree to which an individual perceives the world as threatening, problematic, and distressing [22]. Highly neurotic people tend to be fearful, sad, embarrassed, distrustful, and have difficulty managing stress. The paper begins with a brief review of personality used to explain individual differences in willingness to involve in cognitive efforts, affective motivation and social relationship building in the process of shopping online.

\section{Research Model and Hypotheses}

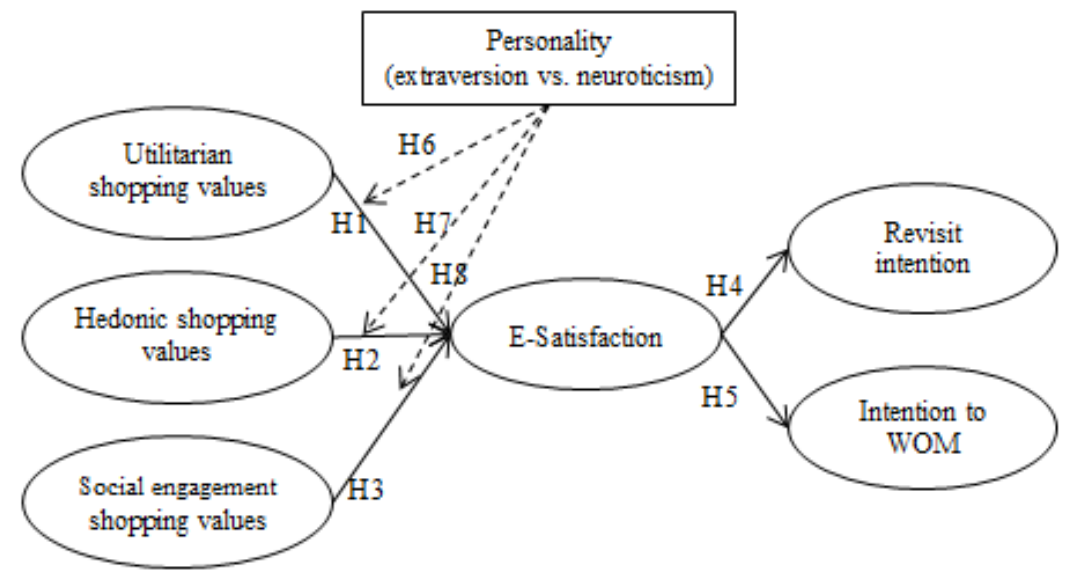

Figure 1.Research Model

\subsection{Shopping Values and e-satisfaction}

Basically motivations for Internet shopping vary, but motivations can be broadly regardedas goal-oriented (utilitarian), fun-seeking (hedonic), and social relationshiporiented (social engagement). These values are required to provide for online shopping business success because of the close relationship among shopping values, customer satisfaction and repurchase [23][24]. First, utilitarian shopping values characterize consumers who focus on a rational problem-solving buying process. According to Schröder\&Zaharia [9], convenience is an important element in characterizing utilitarian shopping values. Convenience includes access-, search-, possession-, transaction- and time-convenience. An effective lodging website provides an easy-to-access channel with fast and uncluttered service so that consumers can conveniently attempt to search information, evaluate alternatives, and perform transaction with minimized cost and time. Thus, compared to offline store channel, online channel is superior in offering services to consumers. Once a convenience-benefit is professed from online websites, then it may be expected that consumers will show favorable attitudes toward patronage intent. In this regard, the following hypothesis is suggested:

H1: Utilitarian shopping values are positively associated with e-satisfaction.

Hedonic shopping values are related to the emotional portion of consumption experiences, which covers excitement, pleasure, enjoyment, and arousal [10]. Evidently, recreational shoppers, who enjoy shopping as a leisure activity, have a more positive attitude toward web retailing [25]. For a decade, a number of research have adapted PAD (pleasure, arousal, dominance) model suggested by Mehrabian\& Russell [12], which revealed that emotional facet of consumption experience increased consumer's satisfaction toward loyalty. Wong et al. found that external store attributes and internal personal enjoyment influence on enhancing satisfaction in offline shopping mall [10]. 
Kim et al. also supported that the provision of hedonic shopping values has become a key source of profits for online business [7]. Especially, in a case of leisure tourism, prospective travelers aim to navigate information related to leisure. Shopping can function as a form of escape and sensory stimulation for consumers who intend to purchase leisure-related products [26]. Recreational shopping in tourism is conductive to pleasurable experiences, which lead to leisure behavior. As such, recreational shoppers who enjoy shopping as a leisure activity, have a more positive attitude toward web. The following hypothesis is formulated for the study:

$\mathrm{H} 2$ : Hedonic shopping values are positivelyassociated with e-satisfaction.

According to Kazakeviciute\&Banyte, shopping offers the chances for having social relationships with other people by exchanging new shopping information such as the best product for the lowest price [27]. Especially, with the emergence of web 2.0 where personal users can create online contents, the greater proportion of the content allows the consumer to co-create his/her personalized online shopping experience [28].In web 2.0 environment, shopping websites as well as social networking sites such as Facebook, blogs, and twitter provide a platform to share ideas, interpretations, and insights for shopping experiences, creating word of mouth effect. Especially, in the lodging industry, where consumers experience intangible services, the effect of social relationship with others may be more influential and meaningful [29]. As purchasing lodging services online is based on search activities for information on the internet, shopping values that consumers seek online are regarded as a significant driver of purchase behaviors. Dlodlo proposes that the information acquired and learned by online consumers will lead to the formation of specific attitudes toward certain brands [11]. Thus, this paper hypothesizes that consumers with high social engagement value from an online shopping experience will develop positive attitudes toward an online provider.

H3: Social engagement shopping values are positivelyassociated with e-satisfaction.

\section{2 e-satisfaction and e-loyalty}

Customer loyalty is a buyer's attachment or deep commitment to a product or service [1], and this common definition can be also applied to e-loyalty. E-loyalty is the customer's satisfaction with an electronic business, resulting in repeat purchasing and positive word-of-mouth behavior [30]. While online customers cannot experience products/services directly, they can search and compare numerous alternatives. Therefore, the relationship between satisfaction and loyalty is stronger online than offline [31]. Although it is difficult to gain loyal customers on the Internet, customer satisfaction with an online provider could motivate them to revisit and stay. Therefore, with respect to the effect of e-satisfactionon e-loyalty, we suggest that a customer's perception of hedonic, utilitarian and social engagementshopping values is a central component of customer satisfaction and loyalty; satisfied customers are likely to repurchase and motivate WOM.

H4: e-Satisfaction is positivelyassociated with revisit intention.

H5: e-Satisfaction is positivelyassociated with intention to WOM.

\subsection{The Moderating Role of Personality}

Research implies that there exists a relationship between value preferences in shopping situations and consumer behavior, as well as psychographic characteristics such as personality features, opinions and interests. As mentioned above, extraversion is characterized as sociable, gregarious, talkative, assertive, active, lively, venturesome, sensation-seeking, and positive self-esteem. On the other hand, neuroticism indicates high anxiety, negative/low self-image, anxious, depressed, guilt feelings, tense, irrational, shy, moody, emotional, worried, insecure, and angry. Considering prior research focusing on 
emotional stability, neuroticism is close to unstable emotion rather than extraversion. People whoare more neurotic are more self-conscious and more vulnerable to emotional hurt and they have stronger negative emotional reactions, keep their word, and tend to displaynegative emotional responses. However, the extraverts show a greater preference for stimulating and active, and are less likely to avoid stressful situations [32].

Previous researchers agreed that people who score high on conscientiousness havemore utilitarian values [2,33]. Conscientious individuals are orderly,responsible, and cautious [34]. Consumers with higher degrees ofconscientiousness tend to learn things from shopping such as information processing,evaluation and forming cognition. This shopping type of conscientiousness trait is more similar to utilitarian shopping motives. Considering conscientiousness trait from extraversion, introverts which are the opposite of extraversion are conscientious. In a research about shopping experiences, Guido et al. stated that when individuals are introverted, their shopping behaviortends to be utilitarian [2]; whereasCosta\& McCrae [32]conclude that by increasing the level of neuroticism, individuals tend to be more impulsive, depressed, anxious and vulnerable. As neurotics possess impulsiveness as well as anxiety, there has been contradictory research in investigating the relationship between neuroticism and utilitarian shopping values. In the research of Mowen\&Spears, research reports that individuals with high neuroticism are compulsive buyers [35]. However, Chetthanmrongchai\& Daviessuggest that the neurotics are more concerned with thatwas happening at the moment than in the past or in the future, so that they are not likely to be compulsive buyers [36]. In sum, prior research suggests that there is no direct relationship between extraversion and utilitarian shopping values; however, there is a direct relationship between neuroticism and utilitarian shopping values. Therefore, this study hypothesizes:

H6: Utilitarian shopping values have a stronger effect on e-satisfaction in the neurotic consumer group than extrinsic.

Most research has found that emotional stability is positively related to hedonic shopping motives [33] and neuroticism represented by unstable emotion will be negatively related to hedonic shopping values. Guido found that compared to neuroticism, extraversion is positively related to hedonistic shoppingvalues [2]. Extrinsic consumers are likely to enjoy shopping activity itself with regarding it as a kind of leisure. Extraverts are also supposed to find excitement induced by the shopping situation according to their hedonic tone and level of situation. Due to these trait differences between extraversion and neuroticism, hedonic shopping values relate more positively to e-satisfaction in an extravert group.

H7: Hedonic shopping values have a stronger effect on e-satisfaction in the extrinsic consumer group than neurotic.

Although extraverts typically partake in more face-to-face interactions and spend less time on the Internet [37], they prefer social interaction especially for online social activities, such as chat rooms [38].Extraverts use online shopping for leisure activities and as a tool to acquire things to share with others [39]. Apart from social interaction, neurotic people don't seem to share their shopping experiences with others via blog or social networking sites. For neurotic consumers social engagement is more frightening than pleasurable. As neurotic consumers recognize online shopping sites as safe environment because of their lack of sociality, they tend to be engaged in online shopping.

H8: Social engagement shopping values have a stronger effect on e-satisfaction in the extrinsic consumer group than the neurotic one. 


\section{Research Methodology}

The lodging industry is selected to test the hypotheses, since the lodging industry hasthe typical B2C characteristics such as customization, active communicational interaction, and efficient transaction. The target respondents in this study are customers over 19 years old who have purchased hotel/pension/condominium rooms online in the three months preceding the survey. Developing an instrument with multiple-item scales for the constructs of interest, a total of 250 questionnaires are distributed and 182are returned. Of these 181 returns, 175are usable and representa response rate of $70.4 \%$.

Most of the measurement items relating to shopping values (utilitarian, hedonic, and social engagement), e-satisfaction, revisit intention and intention to WOM were taken from relevant studies.Utilitarian shopping values are measured with 4 items (e.g., "when Internet shopping online, I tend to look only for products that I need/want", [24]). Hedonic shopping values are also measured with 4 items (e.g., "Internet shopping makes me feel as though I have escaped from daily life", [7,24]). Social engagement shopping values with 4 items are adapted from Dlodlo[11] and Humphreys [15] (e.g., "contacting with other online shoppers gets me exited"). E-satisfaction with 3 items (e.g., "I am relatively satisfied with the Internet shopping experience I have had on travel reservation site"), revisit intentions with 3 items (e.g., "I intend to acquire product information from the Internet shopping site that I regularly use"), and Intention to WOM (e.g., "I will tell more people about this travel reservation site than I've told about mostother sites I've visited") are measured. For each question, respondents were asked to indicate the extent of their agreement on a five-point Likert scale $(1=$ strongly disagree to $5=$ strongly agree). Additionally, this paper used the Eysenck et al.'s personality questionnaire (EPQ), to measure personality. The EPQ consists of 12 measures for each personality type.

\section{Research Results}

\subsection{Unidiemnsionality Assessment}

To assess the unidimensionality of each scale, internal consistency and confirmatory factor analyses are performed. First, a reliability test is used to purify the measurement scale for each construct. All coefficient alphas of the seven constructs surpassed 0.70 criteria for reliability acceptability. To examine an acceptable fit of the proposed measurement model, each of the constructs is evaluated by examining the statistical significance of each estimated loading, and the overall model fit indices are evaluated. All loadings exceed 0.69 , and each indicator $t$-value exceed $9.99(p<.001)$. The $\chi^{2}$ fit statistics shows207.11 with 120 degrees of freedom $(p<0.001)$. RMSEA is .06 , less than the recommended .08 threshold (Newcomb, 1994). The other statistics support the overall measurement quality given the number of indicators $(\chi 2(120)=207.11(\mathrm{P}<.001), \mathrm{GFI}=$ $0.88 ; \mathrm{CFI}=0.98 ; \mathrm{NFI}=0.96 ; \mathrm{AGFI}=0.83 ; \mathrm{RMSEA}=0.06$ ).

Next, the evidence of discriminant validity exists when the proportion of variance extracted in each construct exceeds the square of the zero-order correlation coefficients representing its correlation with other factors. One pair of scales with the highest correlation is e-satisfaction and revisit intention $\left(\Phi=0.62, \Phi^{2}=0.38\right)$. The average extracted estimates are 0.66 and 0.88 , respectively, indicating adequate discriminant validity. Therefore, according to this assessment, the measures have acceptable levels of validity.

\subsection{Structural Equation Models and Hypothesis Testing}

UsingLisrel, a structural equation model is employed to test the hypothesized model.The hypothesized path model shows a good fit to the data, $\chi^{2}=233.45$, $\mathrm{df}=127$ $(p<0.001) ; \mathrm{GFI}=0.87 ; \mathrm{AGFI}=0.83 ; \mathrm{CFI}=0.98 ; \mathrm{NFI}=0.95 ; \mathrm{RMSEA}=0.06$. 
Table 1. Structural Model Test Results

\begin{tabular}{lccl}
\hline \multirow{2}{*}{ Hypothesized relationship } & \multicolumn{3}{c}{ Proposed model } \\
\cline { 2 - 4 } & $\begin{array}{c}\text { Standardized path } \\
\text { coefficient }\end{array}$ & t-value & Results \\
\hline H1 Utilitarian shopping values $\rightarrow$ e-satisfaction & 0.38 & $4.68 * * *$ & Supported \\
H2 Hedonic shopping values $\rightarrow$ e-satisfaction & 0.43 & $6.04 * * *$ & Supported \\
H3 Social engagementshopping values $\rightarrow$ e-satisfaction & 0.22 & $2.77 * * *$ & Supported \\
H4 e-satisfaction $\rightarrow$ revisit intention & 0.78 & $10.09 * * *$ & Supported \\
H5 e-satisfaction $\rightarrow$ intention to WOM & 0.68 & $8.63 * * *$ & Supported \\
\hline$* * * P<.001, \chi 2(127)=233.45, p<.001 ;$ GFI $=0.87$; AGFI $=0.83 ;$ CFI $=0.98 ;$ NFI $=0.95 ;$ RMSEA $=0.06$.
\end{tabular}

As was expected, all structural path estimates are significant. Further, the signs of all structural paths are also consistent with the hypothesized relationships among the latent variables. Within the model, the estimates of the structural coefficients provide the basic tests of the hypothesized relationships. The set of hypotheses $(\mathrm{H} 1, \mathrm{H} 2, \mathrm{H} 3)$ first address the positive relationships among shopping values and e-satisfaction. The effect of utilitarian shopping values (standardized $\gamma_{1}=0.38, p<0.001$ ), hedonic shopping values (standardized $\gamma_{2}=0.43, p<0.001$ ), and social engagement shopping values (standardized $\left.\gamma_{3}=0.22, p<0.001\right)$ on e-satisfaction are significant. H4 and H5 assume the positive relationships among e-satisfaction, revisit intention, and intention to WOM. E-satisfaction has significant effect on revisit intention (standardized $\beta_{1}=0.78, p<0.001$ ) and intention to WOM (standardized $\beta_{2}=0.68, p<0.001$ ). Thus $\mathrm{H} 4$ and H5are also confirmed by the data.

\subsection{Moderation Effect Testing}

The existence of moderating effects was estimated by a multi-group approach using AMOS. In a multi-group test, a hypothesized model is simultaneously fit to the data of each group being considered, while path coefficients, variance, and error terms are constrained to be equal between groups. In order to test the moderation effect of personality between shopping values and e-satisfaction based on a multi-group approach, this study divided the entire sample into two subgroups into neurotic consumer and extrinsic consumer according to whether their overall perception on each personality was above the sample mean. We suggested that utilitarian shopping values have a stronger positive effect on e-satisfaction in neurotic consumers. Upon examining individual paths in the moderating effects model, we found that neuroticism has a significant moderating effect on the association between utilitarian shopping valuesand e-satisfaction, as expected from $\mathrm{H} 5\left(\Delta \chi^{2}=18.12, \mathrm{df}=1, p<.01\right)$. Hence, the extrinsic consumer group displays a stronger positive relationship between social engagement shopping values and esatisfaction supporting $\mathrm{H} 6\left(\Delta \chi^{2}=25.06, \mathrm{df}=1, p<.01\right)$. Contrary to expectation, the moderation effect of extraversion is not significant in the relationship between hedonic shopping values and e-satisfaction $\left(\Delta \chi^{2}=-0.82, \mathrm{df}=1, \mathrm{NS}\right)$.

Table 2. Moderation Test Results

\begin{tabular}{|c|c|c|c|c|c|c|c|}
\hline & \multicolumn{2}{|c|}{ Neuroticism } & \multicolumn{2}{|c|}{ Extraversion } & \multirow[b]{2}{*}{$\Delta \mathrm{DF}$} & \multirow[b]{2}{*}{$\Delta \mathrm{x} 2$} & \multirow[b]{2}{*}{ Result } \\
\hline & \begin{tabular}{|c|} 
Path \\
coefficient
\end{tabular} & t-value & $\begin{array}{c}\text { Path } \\
\text { coefficient }\end{array}$ & t-value & & & \\
\hline $\begin{array}{l}\text { Utilitarian shopping } \\
\text { value } \rightarrow \text { e-satisfaction }\end{array}$ & 0.38 & $4.99^{* * *}$ & 0.26 & $2.25^{* * *}$ & 1 & $\begin{array}{c}18.12 \\
(\mathrm{p}<.01)\end{array}$ & Supported \\
\hline $\begin{array}{l}\text { Hedonic value } \rightarrow \\
\text { e-satisfaction }\end{array}$ & 0.37 & $3.82^{* * * *}$ & 0.45 & $6.07^{* * * *}$ & 1 & $\begin{array}{l}25.06 \\
(\mathrm{p}<.01)\end{array}$ & Supported \\
\hline $\begin{array}{c}\text { Social engagement value } \rightarrow \\
\text { e-satisfaction }\end{array}$ & 0.13 & $1.71^{\mathrm{N} . S}$ & 0.28 & $2.48^{* * * *}$ & 1 & $\begin{array}{l}-0.82 \\
\text { (N.S) }\end{array}$ & Not supported \\
\hline
\end{tabular}

*p $<0.05, * * \mathrm{p}<0.01, * * * \mathrm{p}<0.001$ 


\section{Conclusions and Implications}

This paper focuses on several issues to explain e-loyalty such as revisit intentionand intention to WOM in an online lodging industry. The first goal is to understand three shopping values that have significant influence on e-satisfaction. The second is to provide insights into the complex interrelationships among shopping values, e-satisfaction, and eloyalty. The third goal is to investigate whether or not the moderator of individual personality has a significant impact on e-loyalty, along with e-satisfaction. In the determinants of e-satisfaction, this study shows that consumers' shopping values have a significant impacton e-satisfaction. It is important for online providers to identify who are their target shoppers and the reason why they shop. With the application of comprehensive goals reflecting emotional and cognitive states of shoppers as well as dispositional personality, a more holistic perspective on how to induce consumers' shopping motives is obtained. The results reveal that the antecedents of shopping behaviors are related to the rational motives behind cognitive processes and the affective motives considering personal feelings [2]. The results also imply that the decision to shop online is made by rational reasoning as well as by emotion. This finding has important implications for online retailers planning advertising strategies designed to increase traffic to their websites. Recently, some travel advertisers tell a story and convey value with rich images, displaying a unique experience across very limited digital real estate in order to stimulate the emotional excitement.

Additionally, the study brings forth another aspect of shopping motives regarding social engagement shopping values. The findings suggest that social engagement shopping values via blogs and chatting rooms have a significant role in information intensive lodging industry. In case of tourism and hospitality products, the problem causing from the lack of direct shopping experiences in purchase process is more difficult to overcome because the quality and the perceived benefits of hospitality products can hardly be evaluated before the product is consumed. Due to this limitation of indirect experience, consumers seek to experience vicariously in the way of referring other experienced consumers' stories. This social engagement shopping values drive consumers to shop online. Next, this paper examines the relationships between shopping values, esatisfaction, and e-loyalty in a comprehensive conceptual framework. The results show that e-satisfaction is positively related to e-loyalty and these positive relationships can be reinforced by recognizing shopping values. For instance, hotel guests like to customize what they buy, and $38 \%$ of them are willing to pay $20 \%$ more for customized products and services [40]. Offering customized products and services can be performed by satisfying consumers' needs. Therefore, in order to enhance e-satisfaction toward eloyalty, online retailers should start improving shopping values by providing opportunities for utilitarism, hedonism and social engagement for the shoppers [11]. Finally, the third issue is whether individual personality has a moderating effect on the relationship between shopping values and e-satisfaction. The results show that strongerutilitarian value preference in shopping situation is observed in a neuroticism group than an extraversion group. On the other hand, hedonic shopping values have a stronger effect on e-satisfaction in the extrinsic consumer group than neurotic. Consumers with hedonic value preference in shopping look for excitement and enjoyment coming from new shopping experiences so that this trait is consistent with extraverts'characteristics searching for new opportunities and adventures. Neurotic consumers want to alleviate their anxiety and gain confidence by collecting shopping information about price or time. Therefore, utilitarian value preference is first considered in a neurotic group.

However, the moderating effect of personality in the relationship between social engagement shopping values and e-satisfaction is insignificant. The plausible reason is that a neurotic group prefers cyber activities instead of face-to-face relationship, but they are also not supposed to share their private talks with unknown people in a chatting room 
or twitter. The neurotics' cyber activities are limited to information search or entertaining in online. On the other hand, extraverts are not likely to spend their leisure time in navigating Internet, but they enjoy social relationships in cyber space. In other words, neurotic people tend to spend much time in Internet activities and extraverts involve especially in cyber social relationship among lots of cyber activities. This difference causes the significant moderating effect of extraversion and the insignificant moderating effect of neuroticism. But future research would investigate other personality types in order to expand the implications of the suggested research model.

\section{References}

[1] R. L. Oliver, "Whence customer loyalty?", Journal of Marketing,vol. 63, no. 4, (1999), pp. 33-44.

[2] G. Guido, "Shopping motives, big five factors, and the hedonic/utilitarian shopping value: An integration and factorial study", Innovative Marketing, vol. 2, no. 2, (2006), pp. 57-67.

[3] G. Guido, A. M. Peluso, M. Capestro and M. Miglietta, "An Italian version of the 10-item Big Five Inventory: An application to hedonic and utilitarian shopping values", Personality and Individual Differences, vol. 76, (2015), pp.135-140.

[4] E. M. Tauber, "Why do people shop?", The Journal of Marketing, vol. 79, no. 2, (1972), pp. 46-49.

[5] R. Westbrook and W. C. Black, "Amotivation-basedshoppertypology", Journal of Retailing, vol. 61, (1985), pp. 78-103.

[6] M. Griffin, B. J. Babin and D. Modianos, "Shopping values of Russian consumers: The impact of habituation in a developing economy", Journal of Retailing, vol. 76, no. 1, (2000), pp. 33-52.

[7] C. Kim, R. D. Galliers, J. H. Ryoo and J. Kim, "Factors influencing Internet shopping value and customer repurchase intention", Electronic Commerce Research and Applications, vol. 11, (2012), pp. 374-387.

[8] V. A. Zeithaml, A. Parasuraman and A. Malhotra, "Service quality delivery through web sites: A critical review of extant knowledge", Journal of the Academy of Marketing Science, vol. 30, no. 4, (2002), pp. 362-376.

[9] H. Schröder and S. Zaharia, "Linking multi-channel customer behavior with shopping motives: An empirical investigation of a German retailer", Journal of Retailing and Consumer Service, vol. 15, no. 6, (2008), pp. 452-468.

[10] Y. T.Wong, S. Osman, A. Jamaluddin and B. C. Y. Fah, "Shopping motives, store attributes and shopping enjoyment among Malaysian youth", Journal of Retailing and Consumer Services, vol. 19, no. 2, (2012), pp. 240-248.

[11] N. Dlodlo, "Developing an online shopping value framework for consumers of non-store fashion brands", International Business \& Economics Research Journal, vol. 13, no. 6, (2014), pp. 1359-1374.

[12] Z. Chenand A. J. Dubinsky, "A conceptual model of perceived customer value in e-commerce: A preliminary investigation", Psychology \& Marketing, vol. 20, no. 4, (2003), pp. 323-347.

[13] A. Mehrabian and J. A. Russell, "An approach to environmental psychology", MIT Press, Cambridge, (1974).

[14] K. Bächström, "Shopping as leisure: An exploration of manifoldness and dynamics in consumers shopping experiences", Journal of Retailing and Consumer Services, vol. 18, no. 3, (2011), pp. 200-209.

[15] R. S. Lazarus, "Stress and emotion: a new synthesis", Springer, New York, (1999).

[16] A. Humphreys, "Co-producing experience", Edited E. Malthouse and A. Peck, Medill on Media Engagement, Pine Forge Press, New York, vol. 8,(2010), pp. 95-110.

[17] A. M. Zawadzka, A. S. Kujalowicz and M. Zawisza, "The effects of power on financial aspirations and expenditures in Poland and the UK", Journal of Social Research \& Policy, vol.4, no. 2, (2013), pp. 4158.

[18] S. R. Maddi, "Personality theories: A comparative analysis", Dorsey Press, Homewood, Ill, (1989).

[19] S. B. G. Eysenck, H. J. Eysenck and P. T. Barrett, "A revised version of the psychoticism scale", Personality and Individual Differences, vol. 6, (1985), pp. 21-29.

[20] J. W. Shim and P. Bryant, "Effects of personality types on the use of television genre", Journal of Broadcasting \& Electronic Media, vol. 51, (2007), pp. 287-304.

[21] M. Mikicin, "Relationships between experiencing flow state and personality traits, locus and control and achievement motivation in swimmers", Physical Education and Sport, vol. 51, (2007), pp. 61-67.

[22] R. C. Nemanick and D. C.Munz Jr., "Extraversion and neuroticism, trait mood, and state affect: A hierarchical relationship?", Journal of Social Behavior \& Personality, vol. 12, (1997), pp. 1079-1092.

[23] L. A. Clark and D. Watson, "Temperament: A new paradigm for trait psychology", Edited L.A. Pervin and O. P. John, Handbook of Personality, Guilford Press, New York, (1999), pp. 399-423.

[24] B. J. Babin, W. R. Darden and M. Griffin, "Work and/or fun: measuring hedonic and utillitarian shopping value", Journal of consumer research, vol. 20, no. 4, (1994), pp. 644-656.

[25] E. Bridges and R. Florsheim, "Hedonic and utilitarian shopping goals: The online experience", Journal of Business Research, vol. 61, no. 4, (2008), pp. 304-314. 
[26] J. Baker and K. L. Wakefield, "Excitement at the mall: Determinants and effects on shopping response", Journal of retailing, vol. 74, no. 4, (1998), pp. 515-539.

[27] A. Kazakeviciute and J. Banyte, "The Relationship of Consumers 'Perceived Hedonic Value and Behavior”, Engineering Economics, vol. 23, no. 5, (2012), pp. 532-540.

[28] M. Seraj, "We create, we connect, we respect, therefore we are: Intellectual, social, and cultural value in online communities", Journal of Interactive Marketing, vol. 26, no. 4, (2012), pp. 209-222.

[29] N. B. Ellison and D. Boyd,"Sociality through social network sites", Edited W.H. Dutton, The Oxford Handbook of Internet Studies, Oxford University Press, Oxford, (2013), pp. 151-172.

[30] S. S. Srinivasan and R. Anderson, "E-satisfaction and e-loyalty: A contingency framework", Psychology and Marketing, vol. 20, no. 2, (2003), pp. 122-138.

[31] P. T. Costa Jr and R.R. McCrea, Editor, "Revised NEO Personality Inventory (NEO-PI-R) and NEO Five Factor Inventory (NEO-FFI) manual”, Psychological Assessment Resources, Odessa, FL, (1992).

[32] V. Shankar, A. Smith and A. Rangaswamy, "Customer satisfaction and loyalty in online and offline environments", International Journal of Marketing Research, vol. 20, no. 2, (2003), pp. 153-175.

[33] S. H. Chen and K. P. Lee, "The role of personality traits and perceived values in persuasion: An elaboration likelihood model perspective on online shopping", Social Behavior and Personality: An International Journal, vol. 36, no. 10, (2008), pp. 1379-1399.

[34] L. A. Pervin, D. Cervone and O. P. John, "Personality: theory and research", John Wiley and Sons, Chichester, (2004).

[35] J. C.Mowen and N. Spears, "Understanding compulsive buying among college students: A hierarchical approach", Journal of Consumer Psychology, vol. 8, no. 4, (1999), pp. 407-430.

[36] P. Chetthanmrongchai and G. Davies, "Segmenting the market for food shoppers using attitudes to shopping and to time", British Food Journal, vol. 101, no. 2, (2000), pp. 81-101.

[37] R. N. Landers and J. W. Lounsbury, "An investigation of Big Five and narrow personality traits in relation to Internet usage", Computers in Human Behavior, vol. 22, no. 2,(2006), pp. 283-293.

[38] Y. A. Hamburgerand E. B. Artzi, "The relationship between extraversion and neuroticism and the different uses of the Internet", Computers in Human Behavior, vol. 16, (2003), pp. 441-449.

[39] T. Amiel and S. L. Sargent, "Individual differences in Internet usage motives", Computers in Human Behavior, vol. 20, no. 6, (2004), pp. 711-726.

[40] R. Sherman, "Producing the superior self-strategic comparison and symbolic boundaries among luxury hotel workers", Ethnography, vol. 6, no. 2, (2005), pp. 131-158.

\section{Authors}

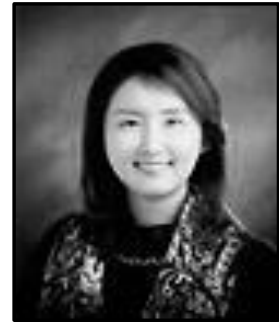

Yun Ji Moon, She has a Ph.D from EwhaWomans University in Management Information Systems. She is an assistant professor in Catholic University of Pusan. Her research interests include adoption of information technology, mobile business, organizational impact of information technology, knowledge management, and e-service quality model. Her papers have appeared in Canadian Journal of Administrative Sciences, Journal of Computer Information Systems, and International Journal of Hospitality Management, Information \& Management, and so on. She can be reached at yjmoon@cup.ac.kr. 
International Journal of $\mathrm{u}-$ and $\mathrm{e}-$ Service, Science and Technology Vol.9, No. 2 (2016) 